\title{
A High-Speed Precision Bearing Internal Grinding Machine and Grinding Process
}

\section{Zhou Chang ( $\nabla$ starismyfriend@163.com )}

Xi'an Jiaotong University

Qian Jia

Xi'an Jiaotong University

Lai Hu

Xi'an Jiaotong University

\section{Original Article}

Keywords: Grade P2 bearing, Internal grinding machine, hydrostatic pressure, high-speed, precise

Posted Date: May 4th, 2021

DOI: https://doi.org/10.21203/rs.3.rs-423958/v1

License: (c) (i) This work is licensed under a Creative Commons Attribution 4.0 International License. Read Full License 


\title{
A High-speed Precision Bearing Internal Grinding Machine and
}

\author{
Grinding Process
}

\author{
Zhou Chang ${ }^{\mathrm{a}^{*}}$ Qian jia ${ }^{\mathrm{b}}$ Lai hu $^{\mathrm{c}}$
}

a.School of mechanical and electrical engineering, Lanzhou Jiaotong University, Lanzhou, Gansu, P.R. China 730070

b.State Key Laboratory for Manufacturing System Engineering, Xi'an Jiaotong University, Xi'an, Shaanxi, P.R. China, 710054

c.State Key Laboratory for Manufacturing System Engineering, Xi'an Jiaotong University, Xi'an, Shaanxi, P.R. China, 710054

E-mail: starismyfriend@163.com

Abstract: In order to meet the requirement of grade P2 bearing grinding, we designed a high-speed internal grinding machine used for bearing raceway and inner circle grinding. The machine adopts T-type layout and 4-axis NC linkage. It is supported by hydrostatic pressure and driven directly by torque motor. Besides, it is equipped with high-speed hydrostatic grinding wheel spindle of ELKA. Our design includes hydrostatic workpiece shaft, hydrostatic turntable and hydrostatic guide rail. The design of this machine can ensure the high-speed grinding process and research has good engineering application value. Finally, the designed precision grinding machine is used to grind the $\mathrm{P} 2$ bearing raceway with reasonable processing technology.

Keywords: Grade P2 bearing; Internal grinding machine; hydrostatic pressure; high-speed; precise

\section{Introduction}

Bearing is an important basic component, its quality directly reflects the national industrial level. At present, China's basic components still can not meet the needs of the main engine matching, many kinds of bearings still need to be imported. It still has space to advance for the accuracy and life of domestic bearings. Especially in high-speed and heavy-duty service conditions, the accuracy and life of domestic bearings can not be guaranteed ${ }^{[1]}$.

Imported rolling bearings can achieve grade P2 accuracy, while it's difficult for domestic rolling bearings. In other words, with the current processing level of bearings in China, it is impossible to process grade P2 rolling bearings in large quantities and efficiently. At present, our country still imports rolling bearings in many industries, for example, our bearings used in high-speed EMUs, still need to be imported. In particular, it should be pointed out that foreign bearing manufacturers have blocked bearing technology, and the export of grade $\mathrm{P} 2$ high precision rolling bearings is strictly limited ${ }^{[2-4]}$.

Grinding as an important processing method of bearing rings, its importance is self-evident ${ }^{[5-6]}$. Bearing raceway is the working surface of bearing, its processing quality has an important impact on the accuracy and lifetime of bearing. The surface quality of bearing raceway after grinding is called surface integrity, which includes two aspects ${ }^{[7-9]}$. One refers to the geometric accuracy of the bearing raceway, usually including roughness, waviness, roundness, raceway sideswing, groove error and so on, and the other one refers to the physical characteristics of the surface of the bearing raceway, usually including residual stress, hardness, metallographic structure, grinding metamorphic layer and so on. Geometric accuracy of bearing raceway usually 
affects bearing accuracy, and the surface physical characteristics of bearing raceway usually affect bearing lifetime. At present, there is still a big gap between domestic bearings and imported bearings in accuracy and lifetime.

In order to make up for the shortcomings of domestic bearings, we should improve the manufacturing technology and equipment of bearings. Grinding machine is an important processing equipment for bearings, which requires our government to invest a lot of time and money to improve the technical index of bearing grinding machine.

At present, the leading foreign bearing grinder manufacturers mainly exist in Europe, Japan, the United States and other western developed countries. Heald in the United States and TOYO in Japan have advanced bearing grinder technology, besides, there are more bearing grinder manufacturers in Europe, such as LIDKOPING, KMT in Swedish; NOVA, MECANDORA, Famir in Italian; WEMA-GLAUCHAU in German; Berthiez in French and so on. The bearing grinder manufactured by these manufacturers, which can process the outer ring, inner ring and end face of the bearing, has a wide processing range, high processing efficiency and accuracy ${ }^{[10,11]}$. However, many bearing grinders in China have problems of low processing efficiency and accuracy, which need to be solved urgently.

\section{Overall design objectives and technical indicators of LGID300}

In this paper, we designed a high-speed precision grinder LGID300 to grind grade P2 angular contact ball bearing 7014. By the grinding machine and grinding technology, we want to achieve the precision and lifetime of 7014: 3000 hours' lifetime for ceramic ball bearings and 2000 hours' lifetime for steel ball bearings. Part technical indicators of 7014 are shown in Table 1.

Table 1 Part of technical indicators of grade P2 angular contact ball bearing 7014

\begin{tabular}{c|c|c|c|c}
\hline bearing & external diameter & internal diameter & width & Channel/Raceway roughness \\
\hline B7014 & $110 \mathrm{~mm}$ & $70 \mathrm{~mm}$ & $20 \mathrm{~mm}$ & $0.02 \mu \mathrm{m}$ \\
\hline
\end{tabular}

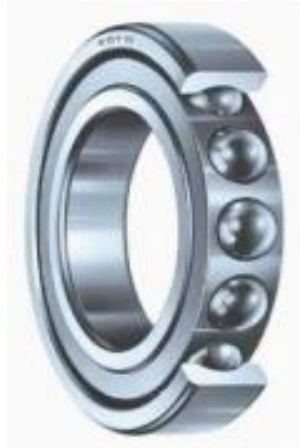

Figure 1 Grade P2 angular contact ball bearing 7014

From Table 1, we can see that the accuracy index of 7014 is high, and its roughness is only $0.02 \mu \mathrm{m}$. The bearing raceway needs ultra-precision machining after grinding, and its roughness can reach $0.02 \mu \mathrm{m}$. Considering all accuracy indexes of grade P2 angular contact ball bearing, we presented the technical indexes of ultra-precision internal grinding machine LGID300 as follows:

(1) Machining accuracy: roundness: $0.3 \mu \mathrm{m}$; roughness: $0.3 \mu \mathrm{m}$.

(2) Workpiece material: quenched bearing steel, hardness: $\leq$ HRC62.

(3) Maximum size of workpiece: inner diameter: $200 \mathrm{~mm}$; width: $160 \mathrm{~mm}$.

(4) Location accuracy: resolution: $0.1 \mu \mathrm{m}$; repetitive positioning accuracy: $0.5 \mu \mathrm{m}$; absolute positioning accuracy: $3 \mu \mathrm{m}$.

(5) $\mathrm{X} / \mathrm{Z}$ axis travel: $250 \mathrm{~mm}$; positioning accuracy: $1 \mu \mathrm{m}$; repetitive positioning accuracy: 0.3 
$\mu \mathrm{m}$; feed speed: 0.01-4.8 m/min; minimum feed: $20 \mathrm{~nm}$; straightness: whole travel $<0.3 \mu \mathrm{m}$.

(6) Turntable travel: \pm 90 degrees; positioning accuracy: 2.5 arc seconds; repetitive positioning accuracy: 1 arc second; rotational speed: 0.01-10 rpm.

(7) Workpiece shaft: hydrostatic spindle, $1500 \mathrm{rpm}$; rotation error $<0.3 \mu \mathrm{m}$.

(8) Grinding wheel axle: maximum speed is $50000 \mathrm{rpm}$; rotation error is less than $0.3 \mu \mathrm{m}$.

(9) Grinding wheel dresser: repetitive positioning accuracy: $1 \mu \mathrm{m}$.

\section{Overall structure scheme of LGID300}

\subsection{Grinding scheme and grinding wheel dressing scheme}

The machining method of inner raceway of outer ring is cut-in grinding, which can also be called profiling grinding. The grinding wheel is dressed by rotary dressing tool. The material of grinding wheel is CBN and the binder is ceramics. When we grind the inner raceway, we use grinding wheel dresser to dress the formed grinding wheel, which requires the workpiece spindle, grinding wheel spindle and turntable feed by interpolation method. When we grind the inner ring of bearing, the machine only needs the workpiece spindle and grinding wheel spindle feed by interpolation method, and does not need the rotation interpolation of turntable.

In order to make full use of the rotational accuracy of the hydrostatic workpiece axis, we made the grinding wheel dresser coaxial with the workpiece axis when we designed the grinding wheel dresser of LGID300. In this way, we guarantee the dressing accuracy and reduce the wear of grinding wheel, besides, the motor and feed motion of the dresser are omitted, so we can save the cost and improved the dressing accuracy at the same time.

\subsection{Overall unit layout of LGID300}

Considering the accuracy of ultra-precision machine tools, we usually use the multi-axis arrangement with less coupling or uncoupling, and adopt the structure of small Abbe error as far as possible, so that the machine structure can achieve high stiffness and stability. The common structural layout of ultra-precision machine includes overlapping, R- $\theta$, turntable and T-type. These layouts are suitable for different processing requirements, each having its own advantages and disadvantages ${ }^{[12]}$.

In the design of LGID300, the maximum diameter of the workpiece is $230 \mathrm{~mm}$, and the width is $160 \mathrm{~mm}$. It is not big so LGID300 belongs to small and medium-sized machine. According to the above reasons, LGID300 adopts T-type layout, which is conducive to improve the rigidity of machine, strengthen the bearing capacity of guideways, and guarantee the processing accuracy.

Internal grinding design scheme: fixture clamped on workpiece axle doing circular motion; CBN grinding wheel on grinding wheel axle doing circular motion at the same time; workpiece axle worktable driving workpiece axle along $X$ direction to do linear feed motion; grinding wheel axle worktable driving grinding wheel axle along $\mathrm{Z}$ direction to do linear feed motion.

Internal grinding requires the center axis of grinding wheel axis to be equal to that of workpiece axis. We designed a heightening pad to make the two center axes equal. Because $\mathrm{Z}$ axis linear motion is similar to $\mathrm{X}$ axis linear motion, we use the same structure design, that is, hydrostatic guide rail and ball screw to complete linear feed.

In the design of LGID300, we designed turntable to dress the grinding wheel and mounted the turntable on the Z-axis worktable. We also refined the mechanical structure considering the assembly and operation of LGID300.

\subsection{Whole machine design of LGID300}

Driving mode: Frame-less torque motor drives the mechanical structure directly. In the linear 
feed axis, the torque motor drives the lead screw directly. In the rotary feed axis, the torque motor drives the rotor directly.

Support mode: LGID300 has linear motion in directions of XZ and rotary motion of workpiece spindle and turntable. Adopting hydrostatic support, we can obtain better motion accuracy and rigidity. So we used hydrostatic guideways in XZ directions and hydrostatic bearings in workpiece spindle and turntable.

Precision spindle: We use hydrostatic spindle on grinding wheel spindle and workpiece spindle. The grinding wheel spindle is purchased and the workpiece spindle is self-made. Grinding wheel spindle adopts 50,000 RPM high precision hydrostatic spindle produced by ELKA Precision Company. The hydrostatic spindle has high rotational speed, high rotational accuracy and good thermal stability, and it is suitable for bearing precision grinding. The main technical data of the motorized spindle are: speed range: 10000-50000 RPMs; built-in permanent magnet motor; maximum sustained power: $8 \mathrm{KW}$; no feedback; tool clamping interface: $17 \mathrm{~mm} / \mathrm{M} 16$; radial motion error under all rotating speeds $<0.06 \mu \mathrm{m}$; axial motion error under all rotating speeds $<0.12 \mu \mathrm{m}$; axial stiffness: $69 \mathrm{~N} / \mu \mathrm{m}$; axial load capacity: $550 \mathrm{~N}$; radial stiffness: $35 \mathrm{~N} / \mu \mathrm{m}$; radial load capacity: $400 \mathrm{~N}$. Figure 2 shows the profile size of ELKA hydrostatic grinding motorized spindle.

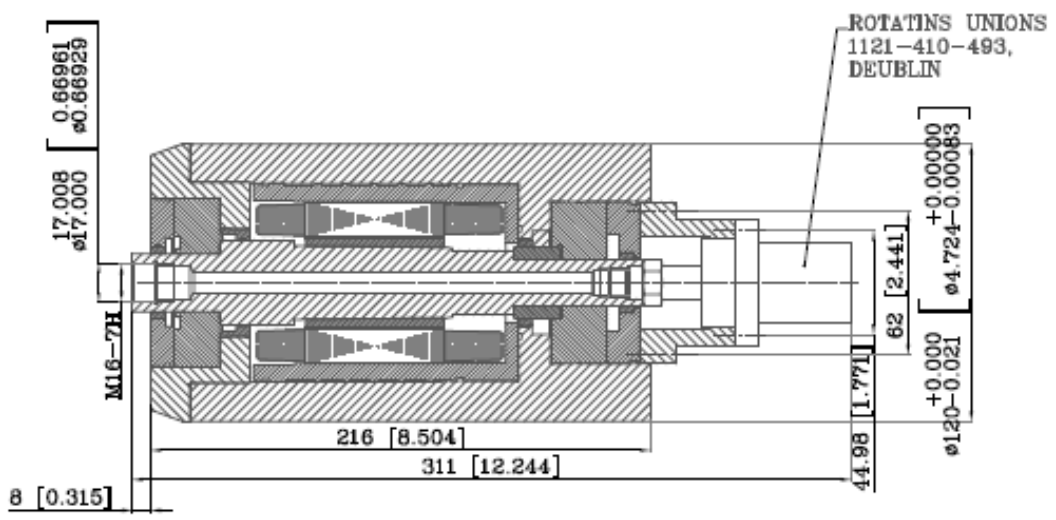

Figure 2 Profile size of ELKA hydrostatic internal grinding spindle

Overall design: Through the analysis of grinding process, we selected the reasonable layout of the whole machine, driving mode, support mode and motorized spindle, obtained the overall design results of LGID300. Specific parameters are shown in Table 2.

Table 2 Main specification parameters of LGID300

\begin{tabular}{|c|c|c|}
\hline \multicolumn{2}{|c|}{ Structure type } & T-type layout and four-axis NC linkage \\
\hline \multicolumn{2}{|c|}{ Outline size } & $2200 \mathrm{~mm} \times 1700 \mathrm{~mm} \times 1950 \mathrm{~mm}$ \\
\hline \multicolumn{2}{|c|}{ Processing object and scope } & $\begin{array}{l}\text { Inner raceway of bearing outer ring and inner } \\
\text { circle of inner ring, etc. } \\
\text { Workpiece diameter } \leq \Phi 230 \mathrm{~mm} \text {, Workpiece } \\
\text { width } \leq 160 \mathrm{~mm}\end{array}$ \\
\hline \multirow{2}{*}{$\begin{array}{l}\text { Servo feed } \\
\text { system }\end{array}$} & Driving mode & $\begin{array}{c}\text { Torque motor }+ \text { precision ball screw }+ \\
\text { hydrostatic guide rail }\end{array}$ \\
\hline & Axial travel & $X$ axis: $250 \mathrm{~mm} 、 Z$ axis: $250 \mathrm{~mm}$ \\
\hline \multicolumn{2}{|c|}{ Rotary table C } & Oil static pressure precision turntable, trave $1 \pm 90^{\circ}$ \\
\hline
\end{tabular}




\begin{tabular}{|c|c|}
\hline Workpiece axis B & Oil static pressure spindle, 2000r/min \\
\hline Grinding wheel spindle & Oil static pressure, maximum speed 50000r/min \\
\hline
\end{tabular}

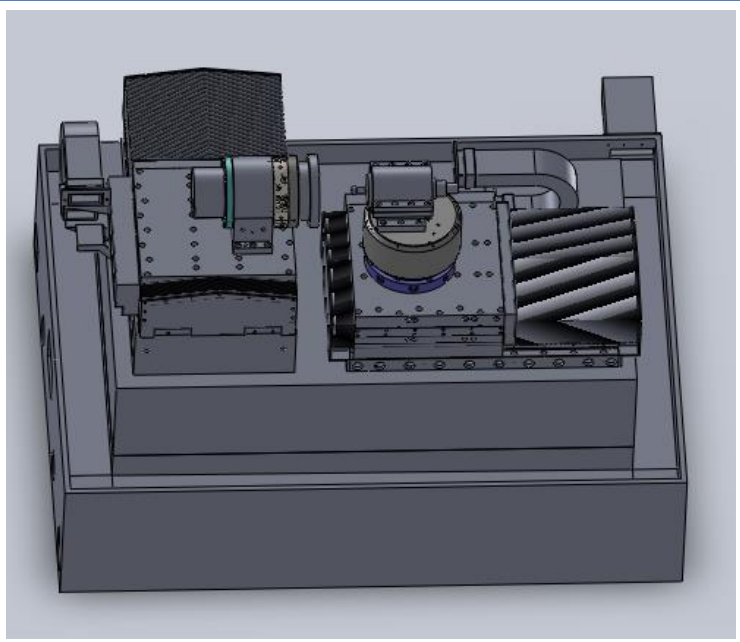

Figure 3 Overall design view of LGID300

\section{Servo drive system design}

\subsection{Screw selection}

We selected the precision ball screw produced by THK in Japan. Considering the cost, we chose the grade $\mathrm{C} 3$ accuracy. Considering the use space, we chose the DIK nuts and select the fixed installation mode at both ends. We used pre-stretching method to assemble the screw and selected angular contact ball bearings produced by German FAG.

According to the design index of linear feed motion axis and THK manual, we selected and calculated the guide, diameter, total length and thread length of the lead screw, and completed the stiffness check. The helical pitch of the lead screw is $5 \mathrm{~mm}$, the diameter is $32 \mathrm{~mm}$, the total length of the lead screw is $852 \mathrm{~mm}$ and the thread length is $590 \mathrm{~mm}$. By choosing and designing the screw, we made it meet the requirement of $250 \mathrm{~mm}$ linear travel of $\mathrm{X}$-axis and Z-axis.

\subsection{Selection of torque motor and servo driver}

The friction coefficient of hydrostatic guideway is very small, which is 0.0005 . The acceleration design index of two linear axes of LGID300 is $0.5 \mathrm{~g}$. In the process of acceleration and deceleration, the driving moment of the motor is mainly to overcome the inertia moment.

The rated speed of the torque motor is $3800 \mathrm{r} / \mathrm{min}$, and the continuous stall torque is $4.90 \mathrm{Nm}$. It can meet the requirements of acceleration, speed and drive of the $\mathrm{X}$ and $\mathrm{Z}$ axes in the technical specifications.

We select the KBMS series frameless brushless motor of Kollmorgen in USA as servo driver to cooperate with $\mathrm{AKD}$ servo driver.

\subsection{Design of detection feedback system}

We use angle encoder to control the speed loop. We select the circular grating of British RENIWHAW. The maximum speed of the grating is $2680 \mathrm{r} / \mathrm{min}$ and the system accuracy is 2.97 arc seconds. After subdivision by 200 times sub divider, the system can meet the requirements of positioning accuracy, repetitive positioning accuracy, feed speed and minimum feed rate for X and $\mathrm{Z}$ linear feed axes.

We use linear grating ruler to control the position loop. We select the grating ruler of HEIDENHAIN Company in Germany, which is an open grating ruler with high precision and low 
price. It is suitable for bearing grinding. The total length of the grating ruler is $270 \mathrm{~mm}$, which meets the requirement of $250 \mathrm{~mm}$ linear travel of $\mathrm{X}$ axis and $\mathrm{Z}$ axis. The signal period of the linear grating is $0.512 \mathrm{um}$, and the subdivision of the sub divider is 100 times. When the A and B signals are frequency doubled 4 times in the numerical control system, the positioning resolution of the axis can reach $1.28 \mathrm{~nm}$, which can meet the requirements of the positioning accuracy and the repetitive positioning accuracy of the $\mathrm{X}$ and $\mathrm{Z}$ linear feed axes.

For feed speed, circular grating and linear grating can also meet the requirements.

\subsection{Results of servo drive system design}

In our design, the servo feed mechanism of $\mathrm{X}$ axis and $\mathrm{Z}$ axis uses the moment motor to drive the lead screw directly through the expansion sleeve. We installed circular grating at the end of the lead screw, and equipped the worktable with linear grating, and we realized the double closed-loop control of the position and speed loop for the feed system, so as to achieve the nano-resolution and sub-micron positioning accuracy of the linear motion axis.

\section{Design of hydrostatic guide rail}

\subsection{Choice of guide form and throttle}

There are two types of hydrostatic guideways, open and closed. The closed hydrostatic guide has better rigidity than the open. There are two modes of oil supply: quantitative mode and constant pressure mode. The cost of constant pressure oil supply is lower. Combining the above two aspects, we selected the liquid closed hydrostatic guide, and the constant pressure oil supply mode.

We use a new type of annular slot throttle in hydrostatic guide rail and hydrostatic bearing of LGID300 ${ }^{[13]}$. Its effective throttle size is annular width $d_{c}$ and annular length $1_{c}$. The structure of annular throttle is shown in Fig. 4, in which the 1-indenter is used to fix the throttle and the 2-' $\mathrm{O}^{\prime}$ shaped sealing ring is used to prevent the oil backflow.

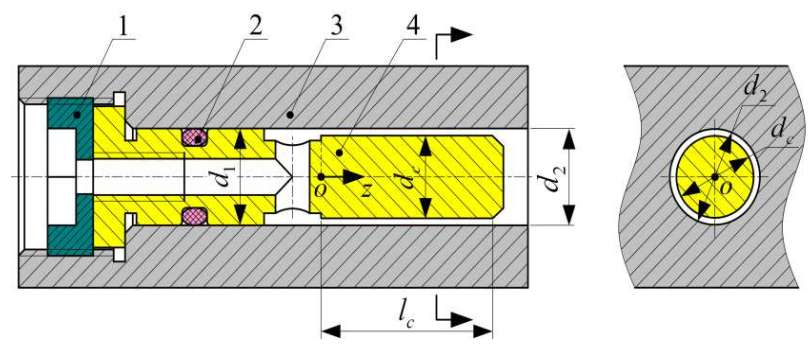

Figure 4 Structure diagram of annular slot throttle

\subsection{Bearing capacity and oil film stiffness}

The total gravity of all parts of $\mathrm{X}$ and $\mathrm{Z}$ linear feed axle guide is about $3000 \mathrm{~N}$ and $3300 \mathrm{~N}$ respectively. The vertical static stiffness of the hydrostatic guide is about $7000 \mathrm{~N} / \mathrm{um}$, and the horizontal static stiffness is about $5000 \mathrm{~N} / \mathrm{um}$ by calculation. Bearing capacity and oil film stiffness can meet the design requirements.

\subsection{Guideway accuracy and oil film thickness}

The two relative moving surfaces of the hydrostatic guideway are in pure liquid friction state, and the oil film stiffness is large, which raise the requirements of the guideway geometric accuracy ${ }^{[14]}$. Usually need:

$$
\Delta \leq\left(\frac{1}{2} \sim \frac{1}{3}\right) h_{0}
$$

Formula: $\Delta$ - Total error of geometric accuracy in the surface of the guide rail; $h_{0}$ - Oil film 
thickness of the guide rail

The oil film thickness of the guide rail should not be too large, so as to avoid reducing the rigidity of the guide rail, and should not be too small also. Generally, the following values are recommended for the design of hydrostatic guideways: the oil film thickness of hydrostatic guideways for medium and small machine tools $h_{0}=15-30 \mu \mathrm{m}$, and the oil film thickness of hydrostatic guideways for large machine tools $h_{0}=30-60 \mu \mathrm{m}$. We adopts $h_{0}=20 \mu \mathrm{m}$.

\subsection{Design results of guide rail structure}

In order to make the oil film uniform, we designed two oil chambers. The hydrostatic guide is composed of the left and right guide bars and the slide saddle. The sliders move with the workbench together. We make the oil circuit and the oil-saving hole on the moving sliders. After all aspects calculating and optimizing of oil film dimension chain $\mathrm{D}_{1}-\mathrm{D}_{2}, \mathrm{D}_{3}-\mathrm{D}_{4}, \mathrm{D}_{6}-\mathrm{D}_{5}$, we designed the dimension of guide as $B=40 \mathrm{~mm}, b=15 \mathrm{~mm}, \mathrm{~L}=245 \mathrm{~mm}, \mathrm{l}=20 \mathrm{~mm}, \mathrm{~h}=20 \mu \mathrm{m}$.

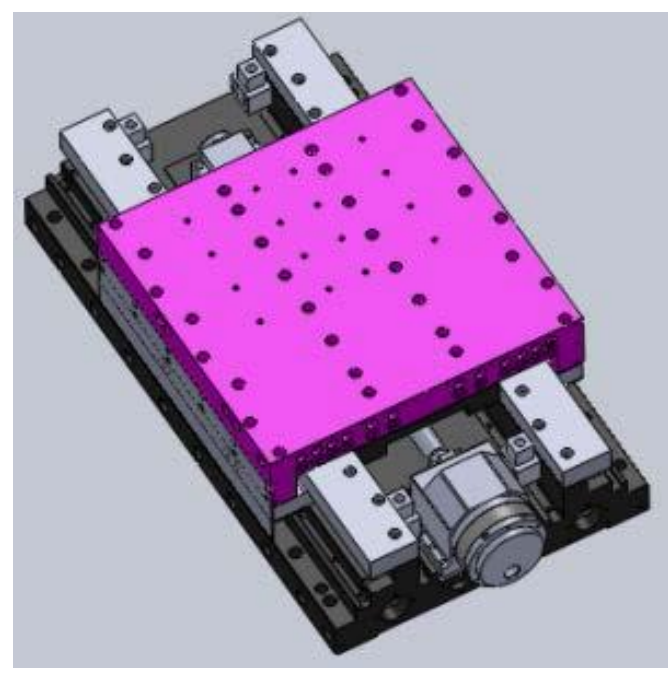

Figure 5 Structural design model of guide rail

\section{Design of hydrostatic rotary parts}

\subsection{General design of hydrostatic bearing}

We adopt the overall design scheme of direct torque motor driving, hydrostatic bearing supporting, non-contact circular grating feedback and computer digital control for the hydrostatic turntable and spindle.

Table 3 Design indexes of hydrostatic bearing

\begin{tabular}{ccc}
\hline Items & Hydrostatic turntable & Hydrostatic spindle \\
\hline Radial motion error & $0.3 \mu \mathrm{m}$ & $0.3 \mu \mathrm{m}$ \\
Axial motion error & $0.3 \mu \mathrm{m}$ & $0.3 \mu \mathrm{m}$ \\
Positioning accuracy & $2.5 \mathrm{arc} \mathrm{seconds}$ & $2.5 \mathrm{arc} \mathrm{seconds}$ \\
Repetitive positioning accuracy & $1 \mathrm{arc} \mathrm{second}$ & $1 \mathrm{arc} \mathrm{second}$ \\
Radial stiffness & $2000 \mathrm{~N} / \mu \mathrm{m}$ & $1000 \mathrm{~N} / \mu \mathrm{m}$ \\
Axial stiffness & $2000 \mathrm{~N} / \mu \mathrm{m}$ & $1000 \mathrm{~N} / \mu \mathrm{m}$ \\
Design speed & $100 \mathrm{r} / \mathrm{min}$ & $1500 \mathrm{r} / \mathrm{min}$ \\
\hline
\end{tabular}

\subsection{Structural design of hydrostatic bearing}

Hydrostatic bearings include two parts: radial hydrostatic bearings and bidirectional thrust 
hydrostatic bearings. Radial hydrostatic bearings mainly bear radial loads, and bi-directional thrust hydrostatic bearings mainly bear axial loads. We adopt the structure of "axle wrap bearing bush" to improve the axial stiffness of the rotating spindle. The hydrostatic bearings use the same throttle as the hydrostatic guide.

\subsection{Torque motor and grating ruler}

The type of the torque motor of hydrostatic turntable is KBMS-57×01-A. The type of the torque motor of hydrostatic spindle is KBMS- $43 \times 03$-A. The parameters of the torque motors is shown in Table 4.

Table 4 Technical parameters of torque motor

\begin{tabular}{ccc}
\hline Items & KBMS-43×03-A & KBMS-57×01-A \\
\hline Rated power & $2.52 \mathrm{~kW}$ & $2.31 \mathrm{KW}$ \\
Rated torque & $21 \mathrm{~N} . \mathrm{m}$ & $18.8 \mathrm{~N} . \mathrm{m}$ \\
Rated speed & $1500 \mathrm{r} / \mathrm{min}$ & $2050 \mathrm{r} / \mathrm{min}$ \\
Rotor inner diameter & $76.28 \mathrm{~mm}$ & $104.17 \mathrm{~mm}$ \\
Rotor outer diameter & $159.28 \mathrm{~mm}$ & $202.90 \mathrm{~mm}$ \\
\hline
\end{tabular}

We select Renishaw's non-contact circular grating for both hydrostatic turntable and spindle. Its nominal inner diameter is $80 \mathrm{~mm}$, outer diameter is $100 \mathrm{~mm}$, and the number of its dividing lines is 15744 . With 200 times sub divider, its resolution can reach 0.41 arc second. Because the motion of hydrostatic bearing is smooth and it has no creeping phenomenon at low speed, we can guarantee the positioning accuracy of $2.5 \mu \mathrm{m}$ and repetitive positioning accuracy of $1 \mu \mathrm{m}$ by the control of actuator.

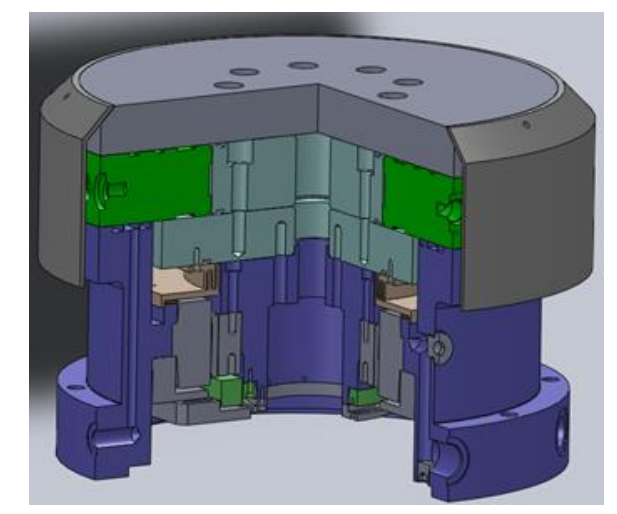

Figure 6 Three-dimensional model of oil hydrostatic turntable

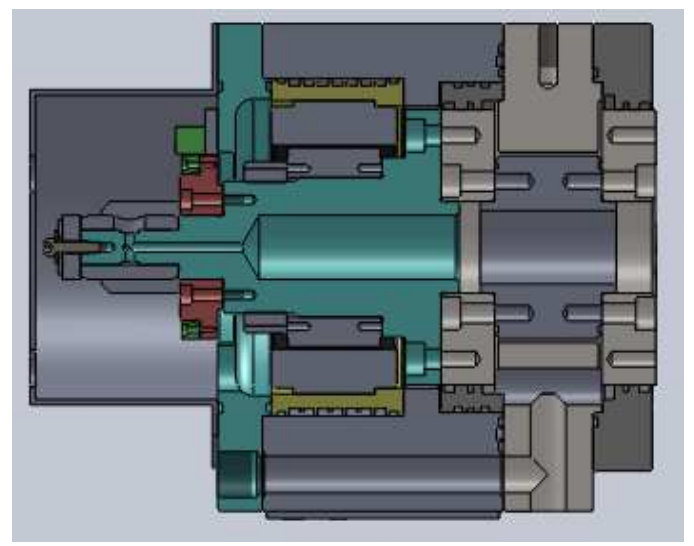

Figure 7 Three-dimensional model of oil hydrostatic spindle 


\section{Accuracy detection}

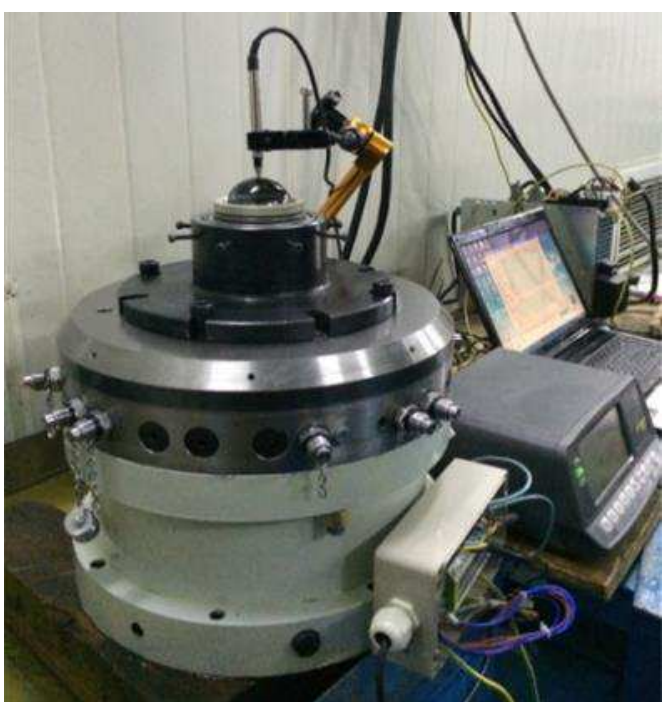

Figure 8 Rotation accuracy detection process

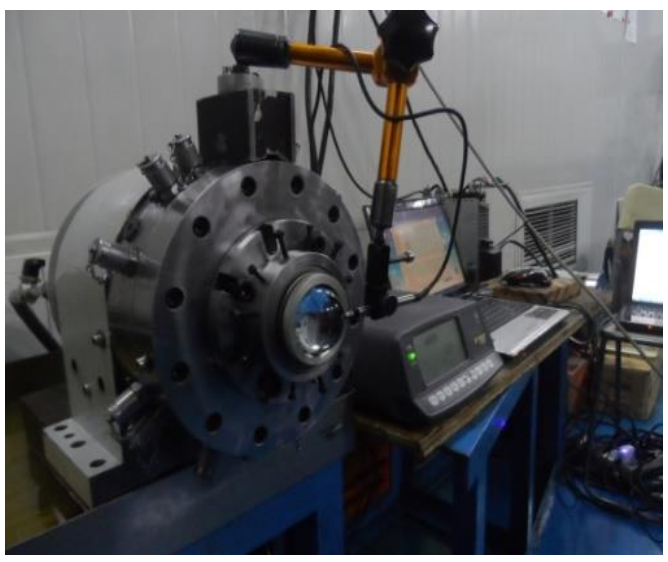

Figure 9 Rotation accuracy detection process

We measured the radial and axial runout errors of the hydrostatic turntable at constant temperature of $20 \pm 2^{\circ} \mathrm{C}$. The radial and axial runout of the hydrostatic turntable are $0.31 \mu \mathrm{m}$ and $0.28 \mu \mathrm{m}$ respectively. The radial and axial runout of the hydrostatic spindle are $0.32 \mu \mathrm{m}$ and 0.28 $\mu \mathrm{m}$ respectively.

\section{8 grinding test}

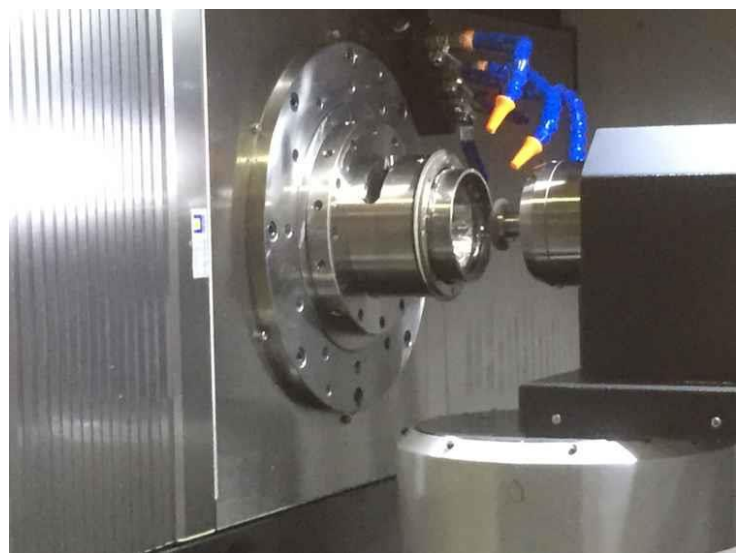

Figure 10 Grinding process 


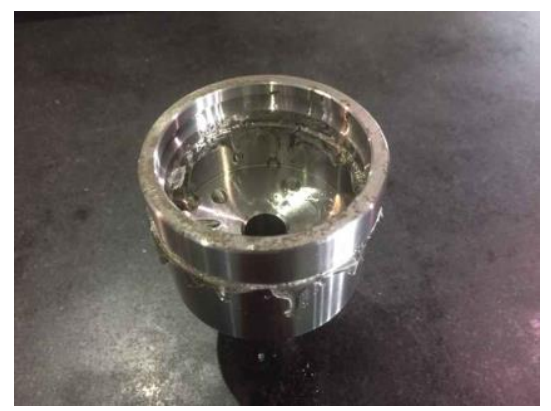

Figure 11 Grinding process

\section{Bonding fixture}

Figure 10 and figure 11 show the grinding bearing raceway, and the grinding process is reliable and effective. The use of adhesive fixture is a major feature of this study.

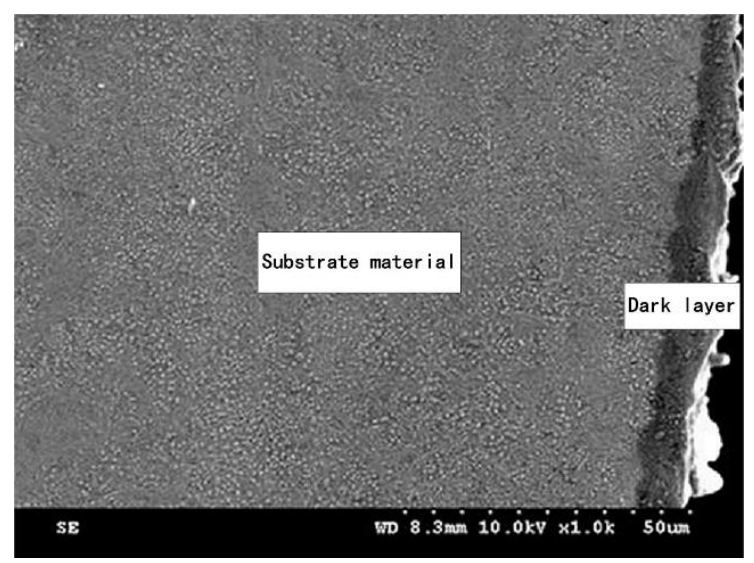

Figure 12 shows micrographs of the affected layers

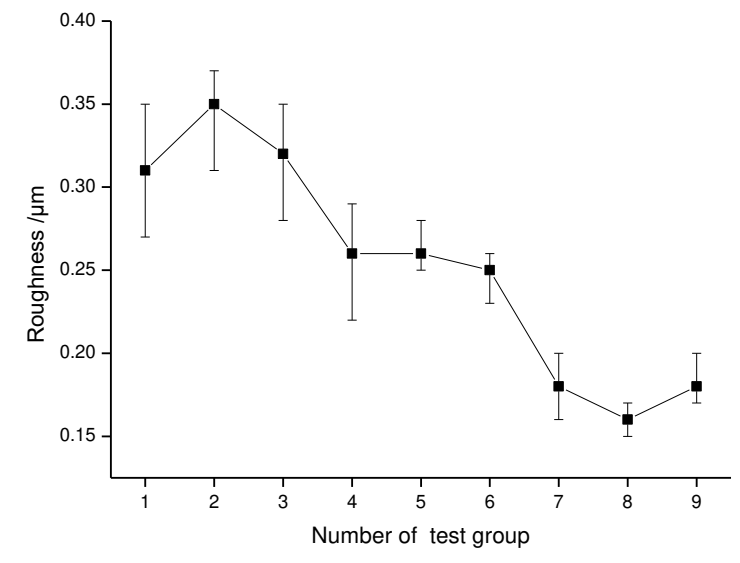

Figure 13 Roughness

With the increase of grinding wheel speed, the grinding roughness decreases to $0.1 \mu \mathrm{m}, \mathrm{P} 2$ level bearing raceway roughness grinding is reasonable. The use of grinding fluid is also less, which meets the requirements of green manufacturing

\section{Conclusion}

1. To meet the requirement of grade P2 bearing grinding, we designed a high-speed internal grinding machine for bearing raceway and inner circle grinding. The line speed of grinding can reach $120 \mathrm{~m} / \mathrm{s}$.

2. We designed the hydrostatic guide with the positioning accuracy of $1 \mu \mathrm{m}$, the repetitive 
positioning accuracy of $0.3 \mu \mathrm{m}$ and the straightness of $0.3 \mu \mathrm{m}$.

3. We designed the hydrostatic turntable and hydrostatic spindle. Their radial and axial runout are both $0.3 \mu \mathrm{m}$.

4. The machine has high processing accuracy. Its roundness is $0.3 \mu \mathrm{m}$, roughness is $0.3 \mu \mathrm{m}$.

5. The machining accuracy meets the requirements of $\mathrm{P} 2$ raceway.

Declarations

Availability of data and materials

The availability of data and materials is real and valid.

Competing interests

No competing interest.

Funding

Funding from the Lanzhou Jiaotong University Foundation is gratefully acknowledged.

Authors' contributions

Zhou Chang conceived of the study, designed the study and collected the data. All authors analysed the data and were involved in writing the manuscript.

Acknowledgments

The authors wish to acknowledge Dr Chen, professor of Xi'an Jiaotong University, for his help in interpreting the significance of the results of this study.

\section{Reference}

[1] Pang G, Qi X, Ma Q, et al. Surface roughness and roundness of bearing raceway machined by floating abrasive polishing and their effects on bearing's running noise[J]. Chinese Journal of Mechanical Engineering, 2014, 27(3): 543-550.

[2] Tao B, Xu W, Pang G, et al. Prediction of bearing raceways superfinishing based on least squares support vector machines[C]. Natural Computation, 2008. ICNC'08. Fourth International Conference on, 2008: 125-129.

[3] $\mathrm{Wu} \mathrm{M}$, Gao $\mathrm{H}$. Experimental study on large size bearing ring raceways' precision polishing with abrasive flowing machine (AFM) method[J]. The International Journal of Advanced Manufacturing Technology, 2016, 83(9-12): 1927-1935.

[4] Wu M, Ren C, Zhang K. ELID groove grinding of ball-bearing raceway and the accuracy durability of the grinding wheel[J]. The International Journal of Advanced Manufacturing Technology, 2015, 79(9-12): 1721-1731.

[5] Chen X, Rowe W, Mccormack D. Analysis of the transitional temperature for tensile residual stress in grinding[J]. Journal of Materials Processing Technology, 2000, 107(1-3): 216-221.

[6] Fergani O, Shao Y, Lazoglu I, et al. Temperature effects on grinding residual stress[J]. Procedia CIRP, 2014, 14: 2-6.

[7] Kruszyński B W, Wójcik R. Residual stress in grinding[J]. Journal of Materials Processing Technology, 2001, 109(3): 254-257.

[8] Mahdi M, Zhang L. Applied mechanics in grinding. Part 7: residual stresses induced by the full coupling of mechanical deformation, thermal deformation and phase transformation[J]. 
International Journal of Machine Tools and Manufacture, 1999, 39(8): 1285-1298.

[9] Paul S, Chattopadhyay A. Effects of cryogenic cooling by liquid nitrogen jet on forces, temperature and surface residual stresses in grinding steels[J]. Cryogenics, 1995, 35(8): 515-523.

[10] Agarwal, Sanjay, Rao, et al. Predictive modeling of force and power based on a new analytical;undeformed chip thickness model in ceramic grinding[J]. International Journal of Machine Tools \& Manufacture, 2013, 65(2): 68-78.

[11] Asano K. Recent development in numerical analysis of rolling bearings basic technology series of bearings[J]. Koyo Engineering Journal, 2002, 160: 65-70. 
Figures

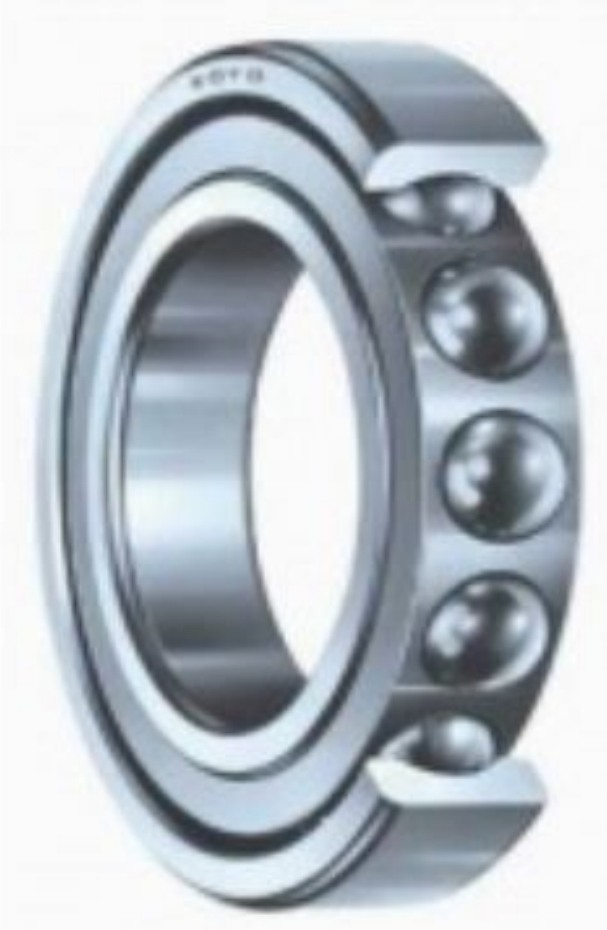

Figure 1

Grade P2 angular contact ball bearing 7014

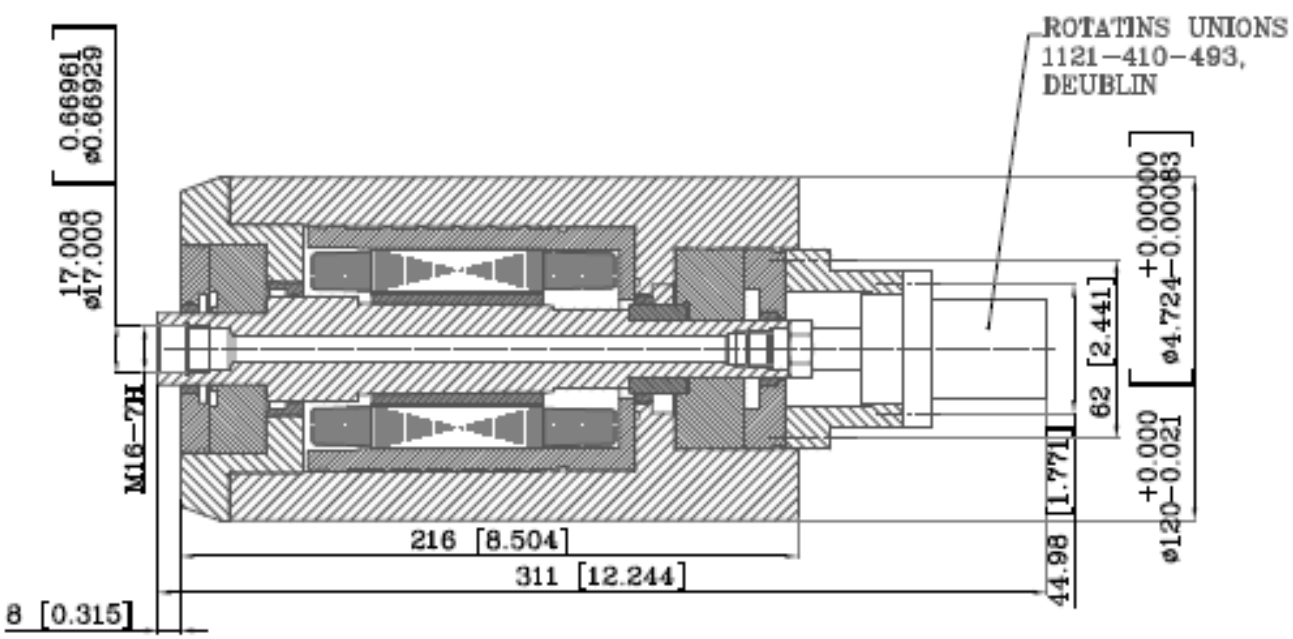

Figure 2

Profile size of ELKA hydrostatic internal grinding spindle 


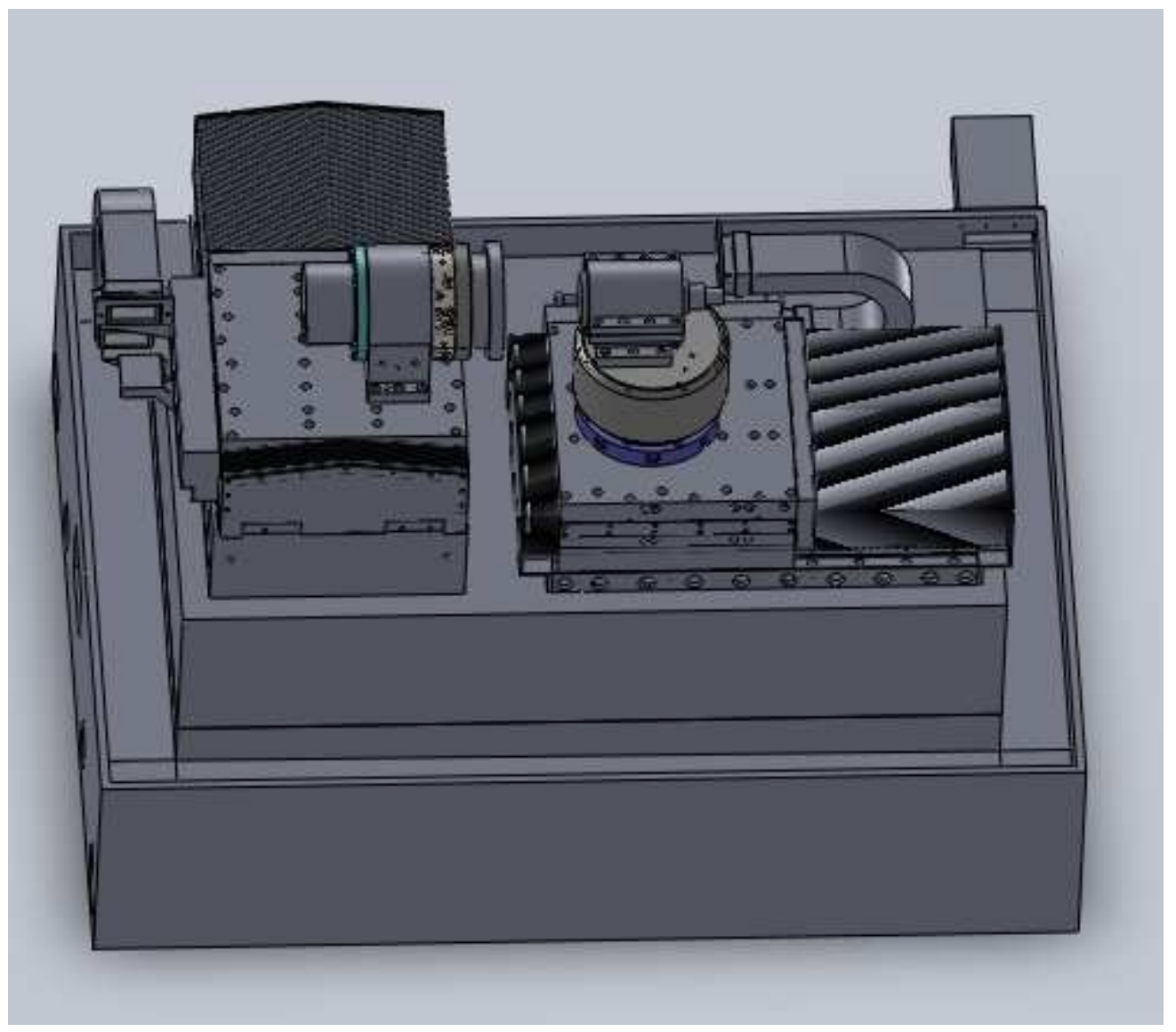

Figure 3

Overall design view of LGID300
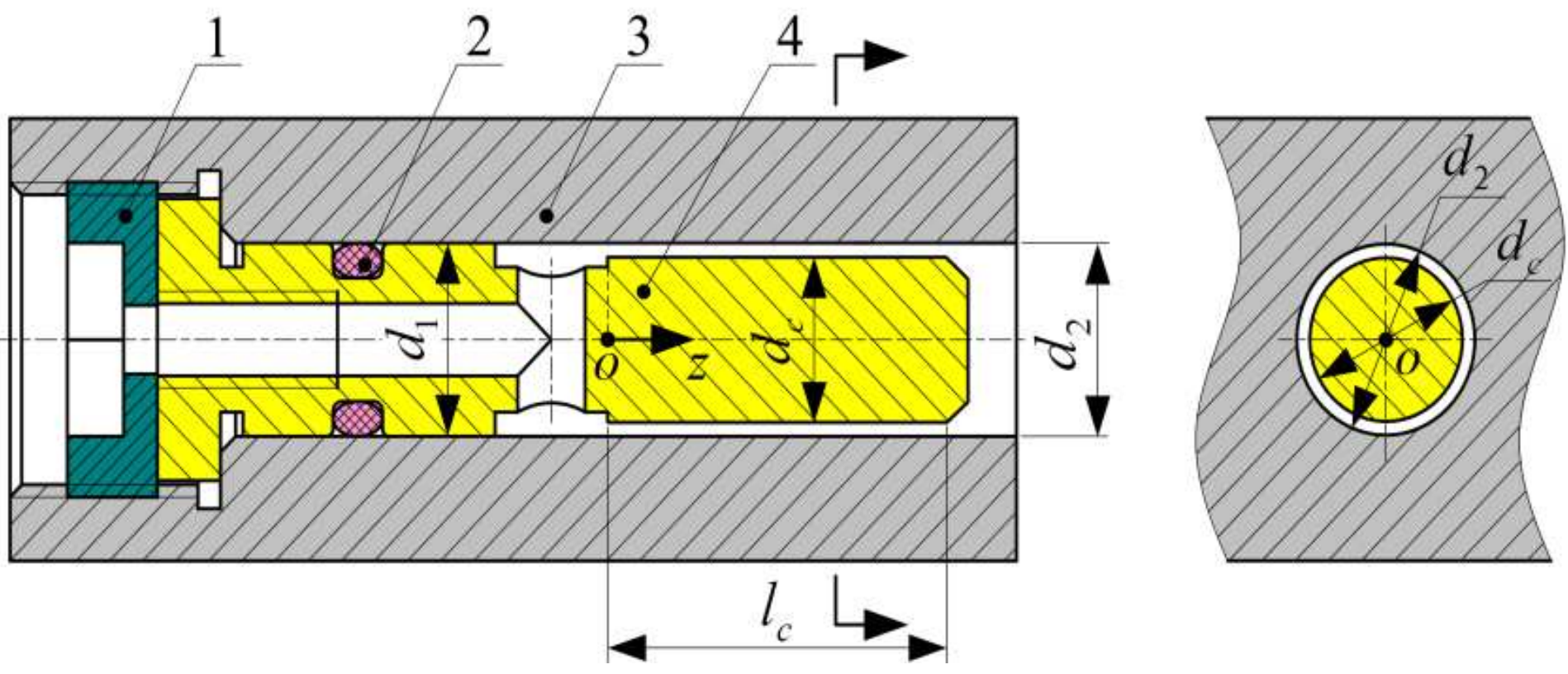

Figure 4

Structure diagram of annular slot throttle 


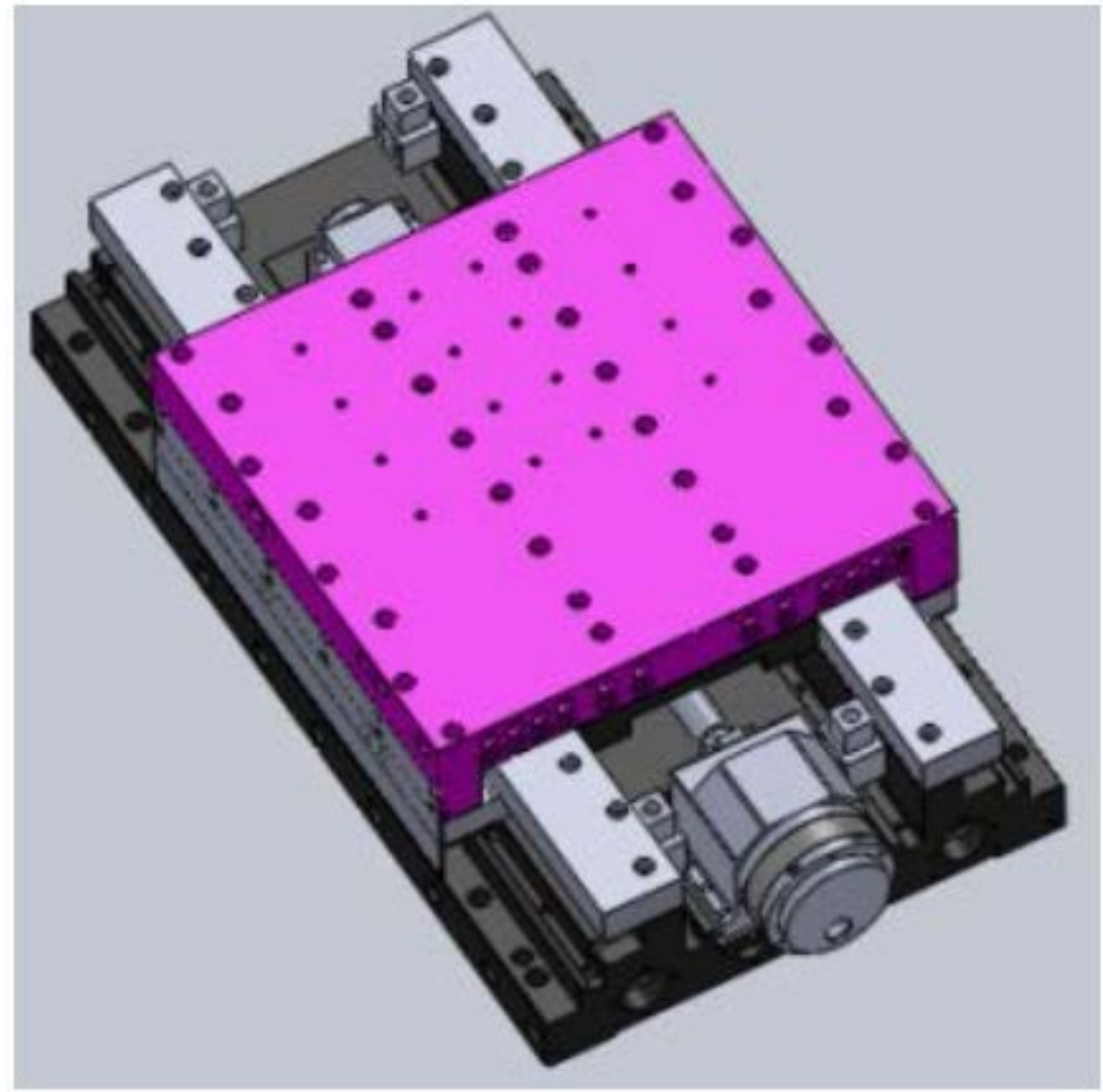

Figure 5

Structural design model of guide rail

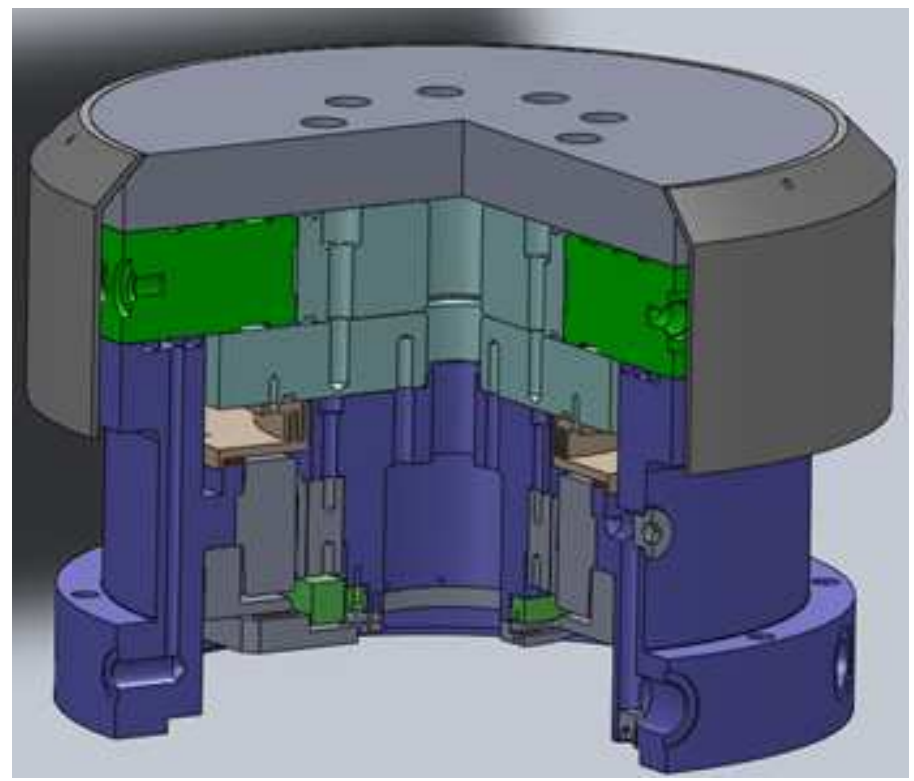

Figure 6

Three-dimensional model of oil hydrostatic turntable 


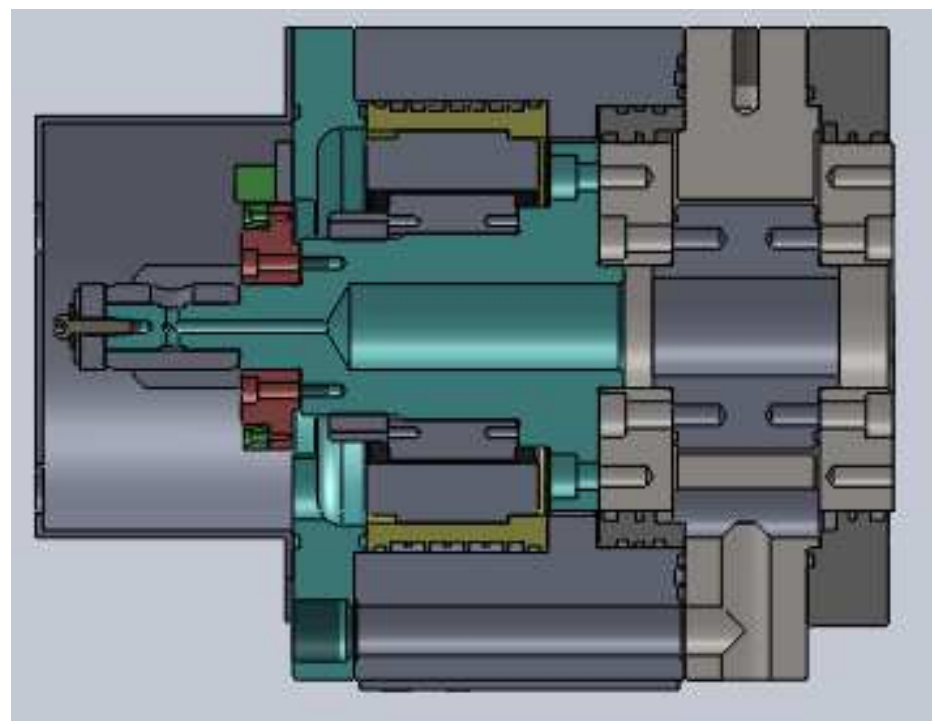

Figure 7

Three-dimensional model of oil hydrostatic spindle

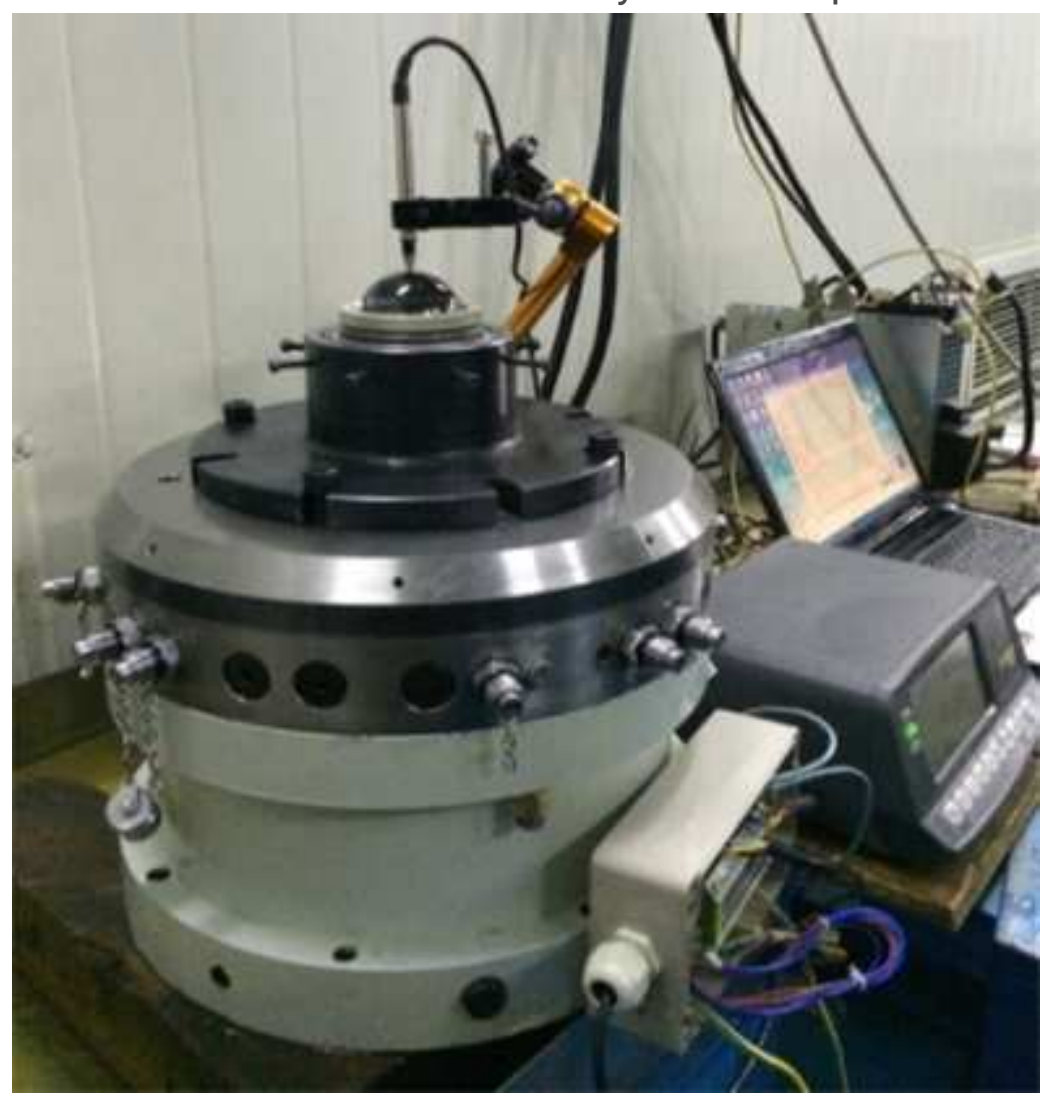

Figure 8

Rotation accuracy detection process 


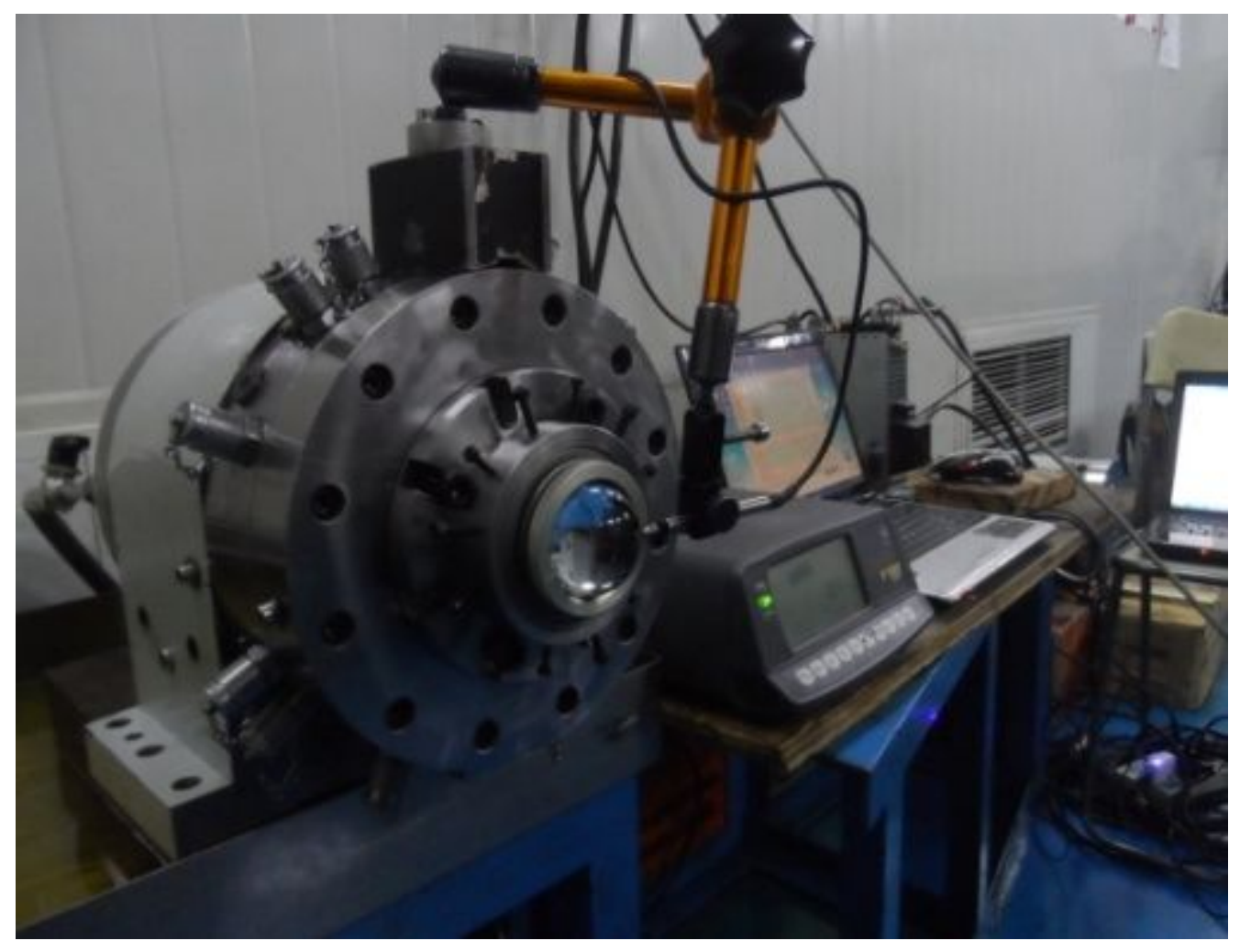

Figure 9

Rotation accuracy detection process 


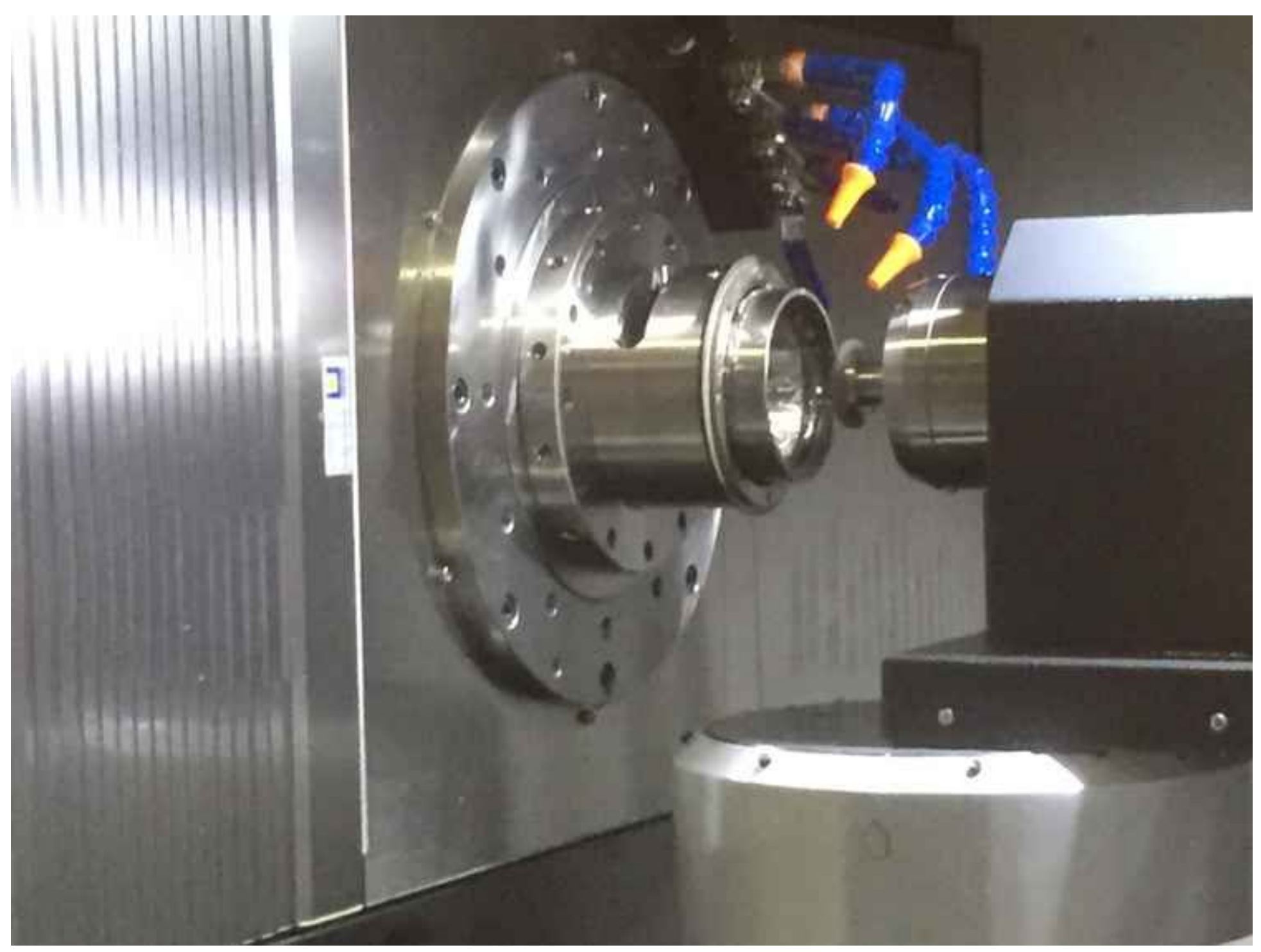

Figure 10

Grinding process 


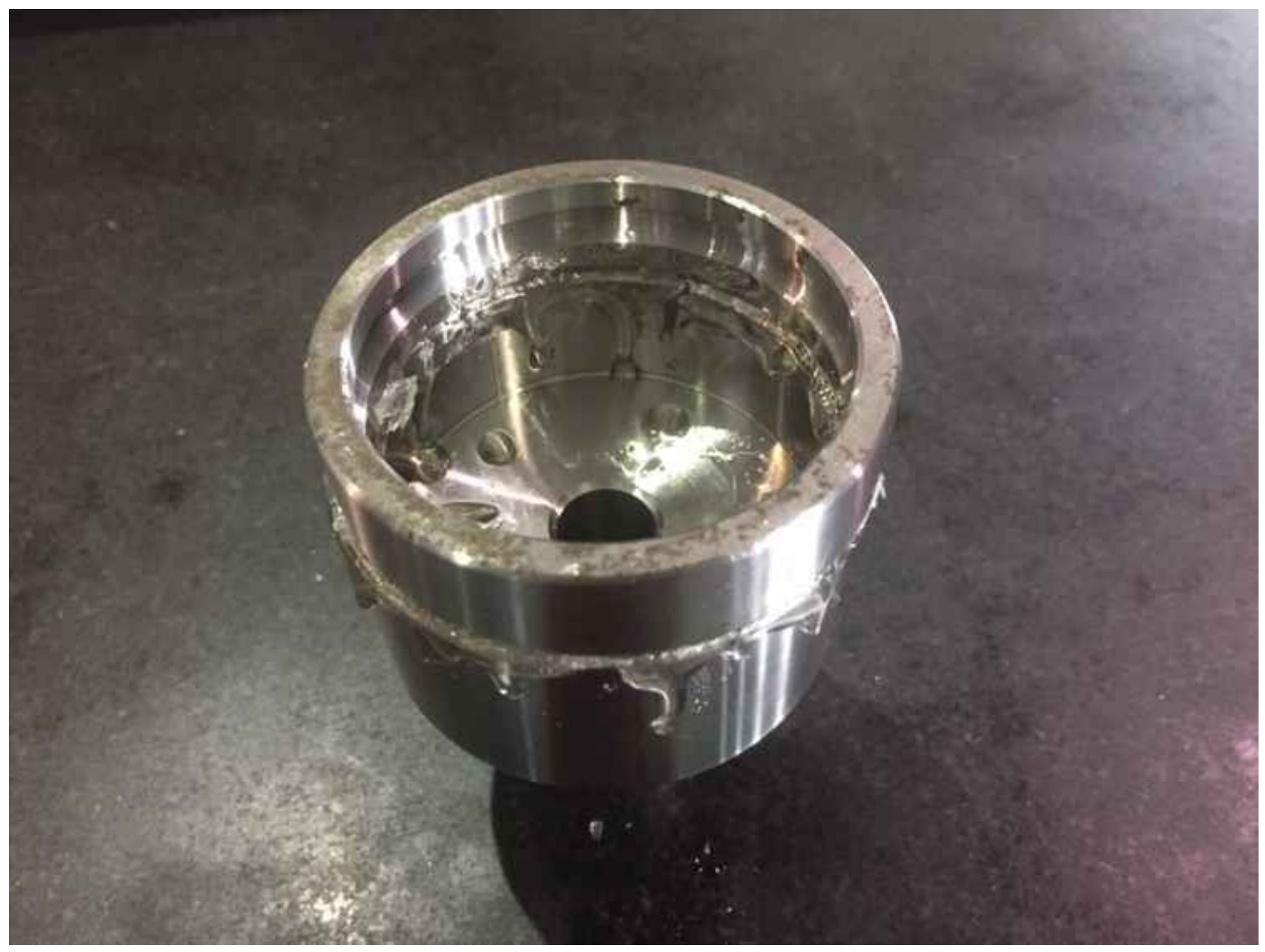

Figure 11

Grinding process Bonding fixture 


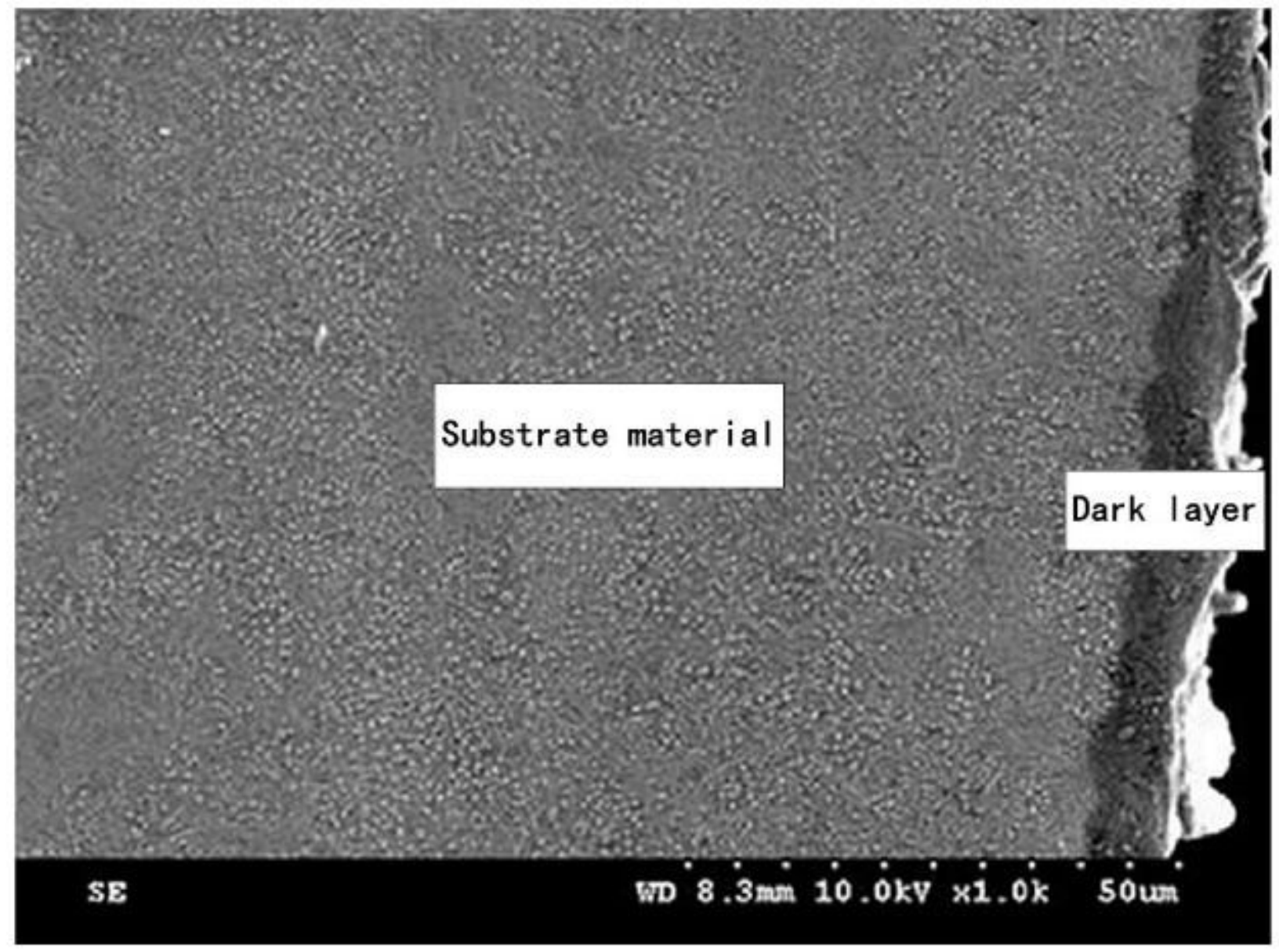

Figure 12

shows micrographs of the affected layers 


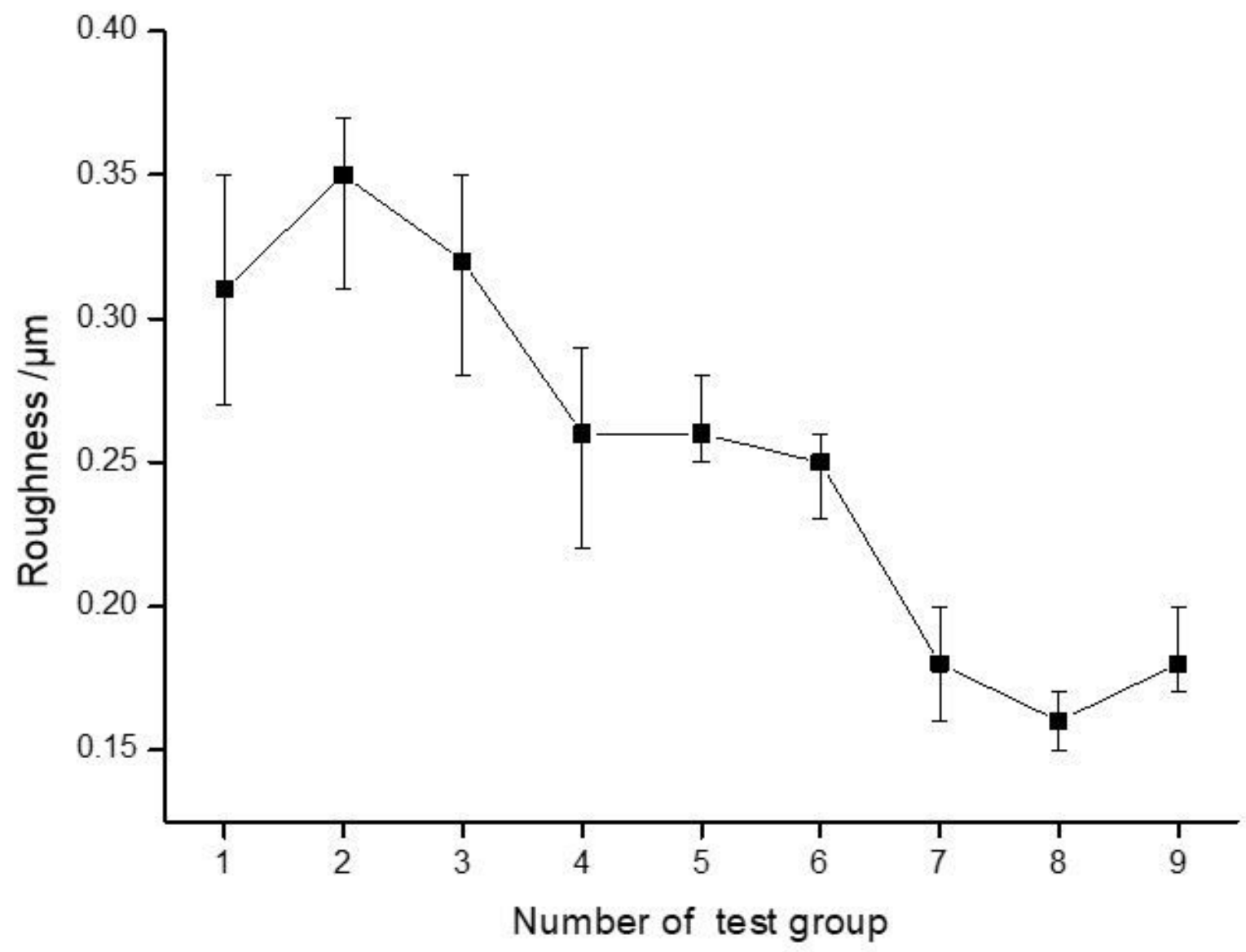

Figure 13

Roughness 